\title{
EDITORIAL
}

\section{Is the Public Outcry for Johnson \& Johnson Jansen's COVID-19 Vaccine Causing Blood Clots Justified?}

As of today, globally, over 139 million people have been infected with SARS-CoV-2 virus and over 2.9 million have died as a result of this infection (1). In the United States, over 31 million people have been diagnosed with COVID-19, a disease caused by SARS-CoV-2 virus and over 565,000 people have encountered a fatal outcome. On February 27, 2021, the US Food \& Drug Administration (FDA) approved the use of Johnson \& Johnson (J\&J) Jansen COVID-19 vaccine for individuals 18 years of age or older under Emergency Use Authorization (2). While the J\&J Jansen COVID-19 vaccine only had $72 \%$ efficacy, a single shot of this vaccine was $100 \%$ effective in preventing death and hospitalization caused by COVID-19 in clinical trials (3). Since its approval, it is estimated that over 6.8 million people in the United States have been vaccinated with J\&J Jansen COVID-19 vaccine (4). Recent reports have confirmed blood clots in six individuals who have received J\&J Jansen COVID19 vaccine (4). All of these six vaccine recipients were females between the ages of 18 and 48 years; symptoms occurred 6-13 days after vaccination, and all had a previous diagnosis of suffering from thrombocytopenia. The form of blood clotting reported in the recipients of J\&J Jansen COVID-19 vaccine is known as the cerebral venous and sinus thrombosis (CVST), a form of disease only encountered in less than $1 \%$ of strokes (5). While it is a rare and severe form of CVST, it is important to recognize that it was only witnessed in $0.000009 \%$ of J\&J Jansen COVID-19 vaccine recipients.

Based on these early reports, on April 13, 2021, both FDA and the Center for Disease Control $\&$ Prevention (CDC) recommended to pause the use of J\&J Jansen COVID-19 vaccine pending further review and to convene a meeting of the Advisory Committee on Immunization Practices (ACIP) to review the available clinical data to make further determination (4). The ACIP met on April 16, 2021 and recommended to extend the pause to allow for additional review of available clinical data (6). While these precautionary actions are justified, the observed complication following J\&J Jansen COVID-19 vaccination must be viewed in light of the fact that the risk of developing thromboembolism (TE) following infection with SARS-CoV-2 and observed mortality is much higher (7). As reported by Malas, et.al, overall arterial TE rate in patients with COVID-19 was $2 \%$ with overall pulmonary embolism rate of $13 \%$. Of equal concern is the observation that pooled odds of mortality are $74 \%$ higher among patients with TE and COVID-19 as compared to those without TE (7). Of note is the fact that the risk of developing blood clots for women of childbearing age using birth control pills is much higher than that observed after vaccination with J\&J Jansen COVID-19 vaccine (8). Equally, the risk of blood clots associated with cigarette smoking is higher than that observed after vaccination with J\&J Jansen COVID-19 vaccine (9).

While the precautionary measures taken by the CDC and the FDA to examine the data in detail is in the best interest of the public, it must be argued that the low risk of blood clot following vaccination with J\&J Jansen COVID-19 vaccine as compared to that following infection with SARS-CoV-2 may justify its continued use to vaccinate people as a means to prevent infection and subsequent hospitalization.

\section{References}

1. COVID-19 Dashboard by the Center for Systems Science and Engineering at Johns Hopkins University. April 16, 2021; 12:01 PM CST. https://coronavirus.jhu.edu/map.html

2. Letter of Emergency Use Authorization from Rear Admiral Denise M. Hinton to Janssen Biotech, Inc., dated February 27 , 2021. https://www.fda.gov/media/146303/download

3. Vaccines and Related Biological Products Advisory Committee Meeting February 26, 2021. FDA Briefing Document Janssen 
Ad26.COV2.S Vaccine for the Prevention of COVID-19. https://www.fda.gov/media/146217/download

4. Joint CDC and FDA Statement on Johnson \& Johnson COVID19 Vaccine. https://www.fda.gov/news-events/pressannouncements/joint-cdc-and-fda-statement-johnson-johnsoncovid-19-vaccine

5. Masuhr F, Einhäupl K. Treatment of cerebral venous and sinus thrombosis. Front Neurol Neurosci. 2008;23:132-43. doi: 10.1159/000111375. PMID: 18004059.

6. CDC Recommendation to Pause Use of Johnson \& Johnson's Janssen COVID-19 Vaccine.

https://www.cdc.gov/coronavirus/2019ncov/vaccines/safety/JJUpdate.html

7. Malas BM, Naazie, IH, et.al. Thromboembolism risk of COVID-19 is high and associated with a higher risk of mortality: A systematic review and meta-analysis. EClinicalMedicine. 2020; 29-30. doi https://doi.org/10.1016/i.eclinm.2020.100639

8. Sidney S, Cheetham TC, et.al. Recent combined hormonal contraceptives (CHCs) and the risk of thromboembolism and other cardiovascular events in new users. Contraception. 2013 Jan;87(1):93-100. doi: 10.1016/j.contraception.2012.09.015. Epub 2012 Oct 19. PMID: 23083525.

9. Cheng Y-J, Liu Z-H, Yao F-J, Zeng W-T, Zheng D-D, Dong YG, et al. (2013) Current and Former Smoking and Risk for Venous Thromboembolism: A Systematic Review and MetaAnalysis. PLoS Med 10(9): e1001515. https://doi.org/10.1371/journal.pmed.1001515

\section{Sohail Rao, MD, MA, DPhil}

Executive Vice President, DHR Health, 5501 S. McColl Road, Edinburg, Texas

President \& Chief Executive Officer, DHR Health Institute for Research \& Development, 5323 S. McColl Road, Edinburg, Texas

Corresponding author email: s.rao@dhr-rgv.com

Disclosures: None

ORCID: Sohail Rao: https://orcid.org/0000-0001-5027$\underline{9992}$ 